\title{
The Laxing of the High-back Vowel: Historical Development and Recent Trends in Minnesota Speech
}

By

Per Moen

Rogaland Regional College

The main purpose of this paper is to see if there is any difference between present-day pronunciation and earlier pronunciations of a group of words spelt in 00 (plus the word butcher). ${ }^{1}$ To find out about this, the pronunciation of 24 words as reflected in 10 dictionaries will be investigated, and the pronunciation of a group of present-day speakers will be compared to the results of previous studies. The informants are students at the University of Minnesota, Minneapolis, and the parents of some of them. They are all Minnesota speakers, and the results will therefore mainly apply to Minnesota speech.

The immediate reason for this investigation is the observation that laxing seems to be a persistent phenomenon in English. Laxing here refers to the change in pronunciation whereby a word which used to be pronounced with a long/tense vowel is now (regularly or frequently) pronounced with a short/lax vowel, e.g. the change $\mid \mathrm{u} / \rightarrow / \mathrm{u} /$ as in root: $/ \mathrm{rut} / \rightarrow / \mathrm{rut} /$.

The following 24 words (with high back vowels) were selected for study: gloom, moon, noon, roost, stoop, aloof, groom, proof, rooster, spook, woof (both as in 'the warp and the woof', and 'the low gruff sound produced by a $\operatorname{dog}^{\prime}$ ), butcher, rook, broom, Cooper, hoof, hoop, roof, room, root, soon, spoon, spoof, and soot. These words (minus spoof) were investigated by Charles H. Grandgent about 1890, and the results reported in Modern Language Notes. I have added spoof because it is a word of relatively recent vintage, and it is of interest both in terms of its vowel, and in terms of its plural form. Does it, for instance, pattern with proof, hoof, and/or roof? 
Grandgent used about 160 informants, chosen with a view to mapping "familiar speech of highly educated persons" (op. cit., p. 230). His findings will first be compared with the pronunciations listed in the following dictionaries: 1) Noah Webster, An American Dictionary of the English Language. Reprinted from 1828 ed. in 1970 by Johnson Reprint Corporation. (Later referred to as Webster I); 2) Webster's New World Dictionary, The World Publishing Company, 1951 (Webster $I I)$; 3) Webster's Third New International Dictionary, G. \& C. Merriam Co., 1966 (Webster 111) 4) The Random House Dictionary \& the English Language, Random House, New York, 1966 (R. H.); 5) J.S. Kenyon \& T. A. Knott, A Pronouncing Dictionary đ American English, G. \& C. Merriam Co., 1953 (K \& K); 6) John Walker, Critical Pronouncing Dictionary, Collins and Hannay, New York, 1823 (Walker); 7) The Oxford English Dictionary, Oxford, 1961 (OED); 8) The Advanced Learner's Dictionary \& Current English, OUP, 1963 (ALD); 9) Everyman's English Pronouncing Dictionary, Thirteenth ed., Dent, 1967 (EPD); 10) J. W. Lewis, A Concise Pronouncing Dictionary \& British and American English, OUP, $1972(\mathcal{F} W L) .{ }^{3}$ These ten dictionaries use different transcription systems. In the following table, however, the symbols used will be /u/ as infool, / $\mathrm{u} /$ as infoot, and $/ \Lambda /$ as in cut. When there are two or more citations for a word the one to the left represents what the dictionary has as the most common pronunciation. ${ }^{4}$

I will first compare the five American English (AE) dictionaries, plus Walker, and also see how the pronunciations listed here agree with Grandgent's findings. The table shows that there is full agreement on the words under A. Grandgent had found that the whole country was "all but unanimous for $/ \mathrm{u} /$ " (op. cit., p. 232). Grandgent also found that there was a very strong preference everywhere for $/ 0 /$ in butcher, rook (group C). This finding agrees with all the dictionaries, except Walker, which has $/ \mathrm{u}$ / in rook. The question is then: Was London pronunciation /ruk/ when Walker's dictionary appeared (1791) or is Walker wrong? Noah Webster, in the Introduction to $W I$, clearly thinks Walker is wrong. He states that "the notation of the sound of 00 by Walker is wrong in most or all the words in which 00 are followed by $\mathrm{k}$, and in some others". ${ }^{5}$ Webster does not allow for the possibility that the pronunciation of some of the words in oo was not settled at the time. He holds that the distinction between the long and the short sound of 00 was well established in a great number of words: "While in England I did not hear a single word of this class pronounced according to 
Table 1.

\begin{tabular}{|c|c|c|c|c|c|c|c|c|c|c|c|c|}
\hline & $\begin{array}{c}\text { W I } \\
1828\end{array}$ & $\begin{array}{l}\text { W II } \\
1951\end{array}$ & $\begin{array}{c}\text { WIII } \\
1966\end{array}$ & $\begin{array}{l}\mathrm{R} \mathrm{H} \\
196\end{array}$ & & $\begin{array}{c}\mathrm{K} \& \mathrm{~K} \\
1953\end{array}$ & $\begin{array}{c}\text { Walker } \\
1823\end{array}$ & $\begin{array}{c}\text { OED } \\
1961\end{array}$ & $\begin{array}{l}\text { ALD } \\
1963\end{array}$ & $\begin{array}{l}\text { EPI } \\
196\end{array}$ & & $\begin{array}{l}\text { JW } \\
19:\end{array}$ \\
\hline \multicolumn{13}{|l|}{ A } \\
\hline GLOOM & $\mathbf{u}$ & $\mathrm{u}$ & $\mathrm{u}$ & $\mathrm{u}$ & & $\mathrm{u}$ & $\mathrm{u}$ & $\mathrm{u}$ & $\mathbf{u}$ & $\mathrm{u}$ & & $\mathrm{u}$ \\
\hline MOON & $\mathrm{u}$ & $\mathrm{u}$ & $\mathrm{u}$ & $\mathrm{u}$ & & $u$ & $\mathrm{u}$ & $u$ & $u$ & u & & $u$ \\
\hline NOON & $\mathrm{u}$ & $\mathrm{u}$ & $\mathrm{u}$ & $\mathrm{u}$ & & $\mathrm{u}$ & $\mathrm{u}$ & $\mathrm{u}$ & $\mathrm{u}$ & $\mathrm{u}$ & & $\mathrm{u}$ \\
\hline ROOST & $\mathrm{u}$ & $\mathrm{u}$ & $\mathrm{u}$ & $\mathrm{u}$ & & $\mathrm{u}$ & $\mathrm{u}$ & $\mathrm{u}$ & $\mathrm{u}$ & $\mathrm{u}$ & & $\mathrm{u}$ \\
\hline STOOP & $\mathrm{u}$ & $\mathrm{u}$ & $\mathrm{u}$ & $\mathrm{u}$ & & $\mathrm{u}$ & $\mathrm{u}$ & $\mathrm{u}$ & $\mathrm{u}$ & $\mathrm{u}$ & & $\mathrm{u}$ \\
\hline $\mathrm{B}$ & & & & & & & & & & & & \\
\hline ALOOF & $\mathrm{u}$ & $\mathrm{u}$ & $\mathrm{u}$ & $\mathrm{u}$ & & $\mathrm{u}$ & $\mathrm{u}$ & $u$ & $u$ & $\mathrm{u}$ & & $\mathbf{u}$ \\
\hline GROOM & $\mathrm{u}$ & u u & $u v$ & $\mathrm{u}$ & 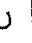 & u $u$ & $\mathbf{u}$ & $\mathrm{u}$ & $u$ & $U$ & $\mathrm{u}$ & $\mathbf{u}$ \\
\hline PROOF & $\mathrm{u}$ & $\mathrm{u}$ & & $\mathrm{u}$ & & u u & $\mathrm{u}$ & $\mathrm{u}$ & $\mathrm{u}$ & $\mathrm{u}$ & & $\mathbf{u}$ \\
\hline ROOSTER & - & $\mathrm{u}$ & $\mathrm{u} u$ & $\mathrm{u}$ & & $\mathrm{u} u$ & - & $\mathrm{u}$ & $\mathrm{u}$ & $\mathrm{u}$ & & - \\
\hline SPOOK & - & $\mathrm{u}$ & $\mathrm{u} u$ & $\mathbf{u}$ & & u $\mathrm{U}$ & - & $\mathrm{u}$ & $\mathrm{u}$ & $\mathrm{u}$ & & $\mathbf{u}$ \\
\hline WOOF & $\mathrm{u}$ & $\mathrm{u}$ & $\cup u$ & $u$ & $\mathrm{u}$ & $\mathrm{u}$ & $u$ & $u$ & $u$ & $\mathrm{u}$ & & $\mathrm{u}$ \\
\hline \multicolumn{13}{|l|}{$\mathrm{C}$} \\
\hline BUTCHER & $u$ & u & $\cup u A$ & & $u$ & $u$ & $u$ & $u$ & $u$ & & $u$ & \\
\hline ROOK & $U$ & $u$ & 0 & & $u$ & $u$ & $\mathrm{u}$ & $u$ & $u$ & & $u$ & \\
\hline \multicolumn{13}{|l|}{$\mathrm{D}$} \\
\hline BROOM & $\mathbf{u}$ & & $\begin{array}{ll}u & u\end{array}$ & $\mathrm{u}$ & $u$ & $u v$ & $u$ & $u$ & $u$ & 0 & $\mathrm{u}$ & $\mathrm{u}$ \\
\hline COOPER & $u$ & u u & $\mathbf{u} u$ & $\mathrm{u}$ & U & $\begin{array}{l}\text { u } \\
\mathrm{u}\end{array}$ & $\mathrm{u}$ & $\mathrm{u}$ & $\mathrm{u}$ & $\mathbf{u}$ & & $\mathrm{u}$ \\
\hline $\mathrm{HOOF}$ & $\mathrm{u}$ & $u \cdot u$ & $u v$ & 0 & $\mathrm{u}$ & $u \quad u$ & $u$ & $\mathrm{u}$ & $\mathrm{u}$ & $\mathrm{u}$ & & $u$ \\
\hline HOOP & $U$ & $\mathbf{u} u$ & $u \quad \mathrm{u}$ & $\mathrm{u}$ & $U$ & $\cup u$ & $\mathrm{u}$ & $\mathbf{u}$ & $\mathrm{u}$ & $\mathrm{u}$ & & $\mathrm{u}$ \\
\hline ROOF & $\mathbf{u}$ & $\mathbf{u} u$ & $\mathrm{u} \cup \Lambda$ & $\mathrm{u}$ & $u$ & u u & $\mathrm{u}$ & $\mathbf{u}$ & $\mathbf{u}$ & $\mathrm{u}$ & & $\mathrm{u}$ \\
\hline ROOM & $u$ & u u & $u \quad u$ & $u$ & $u$ & $u u$ & $\mathrm{u}$ & $\mathrm{u}$ & $u \mathrm{u}$ & $U$ & $\mathrm{u}$ & \\
\hline ROOT & $U$ & u u & u u & $\mathrm{u}$ & $U$ & u u & $\mathrm{u}$ & $\mathrm{u}$ & $\mathrm{u}$ & $\mathrm{u}$ & & $\mathrm{u}$ \\
\hline SOON & $u$ & $\mathbf{u}$ & $u \quad u$ & $\mathrm{u}$ & & $u \quad u$ & $\mathrm{u}$ & $\mathrm{u}$ & $\mathrm{u}$ & $\mathfrak{u}$ & $U$ & $\mathrm{u}$ \\
\hline SOOT & $u$ & $u \quad u$ & $\cup \wedge u$ & & $u$ & $\cup u \Lambda$ & u & $u$ & $u$ & & $U$ & \\
\hline SPOON & $\mathrm{u}$ & $\mathrm{u}$ & $\begin{array}{ll}u & 0\end{array}$ & $\mathrm{u}$ & & u u & $\mathrm{u}$ & $\mathrm{u}$ & $\mathrm{u}$ & u & & $\mathbf{u}$ \\
\hline
\end{tabular}

Walker's notation". (op.cit. $)^{6}$ It seemed inconceivable to Webster that a man "bred or resident in London" (op. cit.) should assign to 00 in book, crook, took and other like words, the same sound as in cool, broom, boot, food. This seems to be a somewhat rash judgement. Stephen Jones, A General Pronouncing and Explanatory Dictionary of the English Language, London, 1805, has /ruk/, thus supporting Webster. But William Percy, The Royal Standard English Dictionary, Brookfield, Mass., 1805, has /ruk/. Webster (1828) says about Percy that his pronunciation is "nearer to the actual usage in England, than that of either of his predecessors (= Sheridan, Walker, Jones) before mentioned" (op.cit.). It seems, therefore, that Walker may not have been as unreliable on the 00 words as Webster claims he is, and also that the process of laxing in the words that Webster criticized 
Walker for transcribing incorrectly was actually completed later. This observation may also be true of soot (see group D), where Webster and Jones have $/ \mathrm{U}$, but Walker and Percy have $/ \mathrm{u} /$. Likewise root, which is /rut/ in Webster, but /rut/ in Walker, Jones and Percy. These facts also make one doubt the reliability of Webster's transcription of Cooper /kupar/ and soon /sun/.

Linguistic atlases, e.g. Harold B. Allen, Linguistic Atlas $₫$ the Upper Midwest (UM), attest other pronunciations of butcher, showing that the long/tense vowel was still heard in the 1940s-50s. In fact three of Allen's informants had retained the earlier folk variant $/ \mathrm{u} /$, and six had unrounded $\mid \Lambda /$. The reader will notice that WIII, which has incorporated many of the findings of Hans Kurath et al., Linguistic Atlas \& New England (Providence: Brown University, 193943), also lists $/ \cup \cup \Lambda /$ in butcher. Butcher is not, of course, one of the 00 words, but it was pronounced with an $/ \mathrm{u} /$ in Middle English. Kurath's Middle English Dictionary shows bocher, bochier, buc(c)er, boucher, bouchier. Although Allen records a few scattered instances of $/ \mathrm{u} /$, the laxing process is otherwise complete in this word.

For the words under B there is also general agreement between the five AE dictionaries. WI has only $/ \mathrm{u} /$, and the other four either list only $/ \mathrm{u} /$ or have $/ \mathrm{u} /$ as less common than $/ \mathrm{u} /$, with the exception of WIII and $R H$, which have $/ 0 /$ as the more common form of woof. One thing to note about the words in this group is that neither WI nor Walker have rooster and spook. The first occurrence of rooster in OED is 1822, and for spook it is 1801 . The rest of the words under investigation all have a long history: soon and soot are found as early as 725 (OED), and the majority go back to before 1200. The spelling 00 can be traced back to about 1600 for most of them, for four of them to before 1400 .

For groom, rooster, spook, woof the laxing process is still in progress. (But not, apparently, in England.) The most common pronunciation, however, is $/ \mathrm{u} /$. This agrees with Grandgent, who says that there is a "very strong preference everywhere for $/ \mathrm{u} /$ ". (op.cit., p. 232).

The words in group D show the greatest variation. W I is the only one that lists only / $/$ for Cooper, root, soon. (But see comments above on the reliability of this transcription.) WI and Walker both have only long/tense / $\mathrm{u}$ / in broom, hoof, roof, room. Judging from the AE dictionaries there seems to be a development from a long/tense to a short/lax vowel in these words. A pronunciation with $/ 0 /$ has grown up beside that with $/ \mathrm{u} /$, but the latter is still too much alive 
to allow us to talk of a change from long/tense to short/lax vowel in these words since ca. 1800. (In my material this development is not evidenced till after 1800 , but this need not necessarily mean that the pronunciation with $/ 0 /$ was not common before this date.) Grandgent says that the pronunciation of these words "seems to follow no etymological principle, and shows different dialect divisions for the different words". (op. cit., p. 232).

The last group of words also reveals the (necessarily) arbitrary nature of some of the decisions that dictionarymakers have to make. For example, W $I I$ and $\mathrm{RH}$ list $/ \mathrm{u} /$ as the most common form for hoop: $W I I I$ and $K \& K$ have $/ 0 /$ For hoof, W11, W III and $\mathrm{RH}$ have / $U /$ first: $K \& K$ has $/ \mathbf{u} /$ as the most common form. And, in group B, $W I I$ and $K \& K$ have only $/ u /$ in woof (as in 'the warp and the ...') ; W III and R H have $/ U /$ as the most common form.

A comparison of the $\mathrm{AE}$ and $\mathrm{BE}$ dictionaries reveals that laxing is less noticeable in standard BE. The AE dictionaries show evidence of laxing in all ten words under $\mathrm{D}$, while this process appears to have affected only three of these words in BE (plus soon in EPD only.) For none of the 24 words does laxing seem to be more common in BE than in AE. It might be interesting to see whether there have been any recent changes in BE. For this one would need more detailed information than what can be gleaned from pronouncing dictionaries.

To find out how these 23 words (plus spoof) are pronounced by young Minnesota speakers today, 30 students at the University of Minnesota were interviewed. Most of them were first-year students. The interviews were conducted in such a way as to hide the fact that it was chiefly the informants' pronunciation that was being investigated. They were asked "What do you call ...", not "How do you say ..."'. (A few of them, however, caught on to what was going on towards the end of the interview.) Some of the words could not be elicited without recourse to spelling. Woof, as in 'the warp and the woof', was unknown to nearly all the informants; a few of them did not know the meaning of aloof. (Many of the students seemed to have a rather limited vocabulary.)

Forty-five more students replied to a questionnaire; 22 females and 23 males, all raised in Minnesota. Part of the instruction to the informants was: "In your own speech, do the vowel sounds in the following words rhyme with those of fool, foot, or cut? Put a checkmark in the appropriate column". The questionnaire was used partly to get a larger sample of this type of informant. It was also 
intended to test the reliability of this type of questionnaire. This was found to be important because the parents of the students that had been interviewed were sent questionnaires with the same wording, but with fewer items. (Aloof, groom, woof (as in 'the warp and the ...'), broom, hoof, hoop, roof, room, root, soot - most of which had shown some variation.)? Nineteen parents, with a Minnesota background, replied. Since this is not a very large group of informants, the results should be interpreted with caution.

The reaction of the parents was sought for the following reasons: First, it was desired to find out what differences, if any, there might be between their speech and that of their children. Was there, for instance, a discernible development toward laxing during the last generation? (Some students had said they thought some of the 24 words were pronounced differently by their parents.) Second, there are no other studies that can be used for a word for word comparison of the speech of my young informants and that of the older generation. Charles H. Grandgent's article has no information on specifically Minnesota or Upper Midwest speech, since he divides the country into four geographical areas: the South, the West, New England, and the North, which also includes New England and the West. ${ }^{8}$ Harold B. Allen's The Linguistic Atlas $₫$ the Upper Midwest (UM), has information on ten of the 24 words under investigation here. Comparisons with $U M$ will be made frequently. There are, however, some problems involved. As a result of the way the percentages were arrived at in UM, they do not always add up to $100 \%$. (Alternatives by speakers were computed in each group.) Also, the figures for Types I, II, III speakers respectively are the average of all Upper Midwest speakers (Mn., Ia., N.D., S.D., Nb.), not specifically Minnesota speakers; and the figures for Minnesota speakers comprise all three types of informants.

The results of the interviews and the questionnaires are summarized in Table 2.

Explanation of figures in Table 2:

Aloof. The group I informants who had $/ \Lambda /$ were not familiar with this word.

Groom. Some group I informants had a pronunciation that was impressionistically midway between $/ \mathrm{u} /$ and $/ 0 /$. The same is true of broom, room.

Woof (as in 'the warp and the woof'). Only a few in group I knew this word. Two informants suggested either $/ \mathrm{u} /$ or $/ \mathrm{u}$, and 
Table 2. Group I informants: (30) students interviewed; II: (45) students replying to g tionnaires; III: (19) parents replying to questionnaires.

\begin{tabular}{|c|c|c|c|c|c|c|c|c|c|}
\hline & I & II & $\begin{array}{c}(\%) \\
\text { III } \\
\end{array}$ & I & II & $\begin{array}{l}(\%) \\
\text { III } \\
\end{array}$ & & II & $\begin{array}{r}(\%) \\
I] \\
\end{array}$ \\
\hline \multicolumn{10}{|l|}{ A } \\
\hline GLOOM & 100 & 100 & & & & & & & \\
\hline MOON & 100 & 100 & & & & & & & \\
\hline NOON & 100 & 100 & & & & & & & \\
\hline ROOST & 100 & 100 & & & & & & & \\
\hline STOOP & 100 & 93.3 & & & 6.7 & & & & \\
\hline \multicolumn{10}{|l|}{ B } \\
\hline ALOOF & 86.7 & 91.1 & 89.5 & & 6.7 & 10.5 & 13.3 & 2.2 & \\
\hline GROOM & 96.7 & 100 & 100 & 3.3 & & & & & \\
\hline PROOF & 100 & 91.1 & & & 8.9 & & & & \\
\hline ROOSTER & 100 & 93.3 & & & 6.7 & & & & \\
\hline SPOOK & 100 & 95.6 & & & 4.4 & & & & \\
\hline WOOF (in weaving) & 56.7 & 46.7 & 10.5 & 26.6 & 40 & 89.5 & & 2.2 & \\
\hline WOOF (barking) & 6.7 & 11.1 & & 93.3 & 82.2 & & & & \\
\hline \multicolumn{10}{|l|}{ C } \\
\hline BUTCHER & & & & 100 & 91.1 & & & 8.9 & \\
\hline ROOK & & & & 100 & 97.8 & & & 2.2 & \\
\hline \multicolumn{10}{|l|}{ D } \\
\hline BROOM & 93.3 & 89.9 & 94.7 & 6.7 & 11.1 & 5.3 & & & \\
\hline Cooper & 100 & 93.3 & & & & & & 6.7 & \\
\hline HOOF & 3.3 & 8.9 & 10.5 & 96.7 & 91.1 & 89.5 & & & \\
\hline HOOP & 100 & 97.8 & 100 & & 2.2 & & & & \\
\hline ROOF & 10 & 24.5 & 15.8 & 90 & 75.5 & 84.2 & & & \\
\hline ROOM & 96.7 & 93.3 & 89.5 & 3.3 & 6.7 & 10.5 & & & \\
\hline ROOT & 23.3 & 11.1 & 36.8 & 76.7 & 89.9 & 57.8 & & & \\
\hline SOON & 100 & 100 & & & & & & & \\
\hline SPOON & 100 & 97.8 & & & 2.2 & & & & \\
\hline SPOOF & 100 & 86.7 & & & 13.3 & & & & \\
\hline SOOT & 100 & $2 \cdot 2$ & & & 93.3 & 94.6 & & 2.2 & \\
\hline
\end{tabular}

two just did not know how to pronounce it. Five group II informants left it blank.

Woof ('low gruff sound produced by a dog'). Three group II infs. left it blank.

Soot. One group II inf. left it blank.

There is generally a close correspondence between the results of the interviews and the student questionnaire. One fairly consistent difference is that there is a higher frequency of $/ \mathbf{u} /$ in the interviews. Aloof, groom, hoof, roof are exceptions to this tendency. The last two are interesting, and will be commented on later. On the whole, 
however, the correspondence between the interviewer's and the informants' own impression is close enough for group I and II informants to be lumped together for the purpose of comparing the speech of the 18-19-year-olds with that of their parents' generation. By the same token the results of the questionnaires sent to the parents are also felt to be reasonably reliable.

All group I informants had $/ \mathrm{u} /$ in the words under $\mathrm{A}$, which agrees with the ten dictionaries, and Grandgent. All of them also had the short/lax vowel in the words under $\mathrm{C}$ : butcher and rook. One informant said he had heard /'but/ər/, and two had heard/'bstfor/. Three of Allen's informants had retained the eastern folk pronunciation $/ \mathrm{u} /$, and six had unrounded $/ \Lambda /$. The $1 \mathrm{~J} / \mathrm{in}$ butcher, rook of some of my informants in group I was produced with very little liprounding, but was felt to be closer to the vowel of foot than that of cut, and therefore impressionistically judged to be an $/ 0 /$. It is interesting to see that four group II informants judge their vowel in butcher to rhyme with cut, and one does the same for rook. Allen says about the occurrence of $/ \Lambda /$ in his material that it "may well be a new development consistent with a tendency toward the unrounding of rounded vowels". (op. cit., Vol. 3, p. 285.)

This seems to be borne out by my material as well. (See also aloof, woof, root, soot in Table 2.) Allen found that the form $/ \mathrm{s} \Lambda t /$ was not chosen at all by "cultivated" speakers. In my material a student and a tax accountant have this pronunciation, so this may be changing. (But two swallows do not make a summer.) Three group II informants had $/ 0 /$ in stoop; apart from this, there was complete agreement on the pronunciation of the first five words in the table.

There is less uniformity in the pronunciation of the words in section B. For all of them, except woof, there is a strong preference for the long/tense $/ \mathrm{u} /$. Woof of all the 24 words shows the greatest difference between the pronunciation of students and parents. As already mentioned, woof (in weaving) was unknown to nearly all group I informants. It can, therefore, be safely assumed that many of group II informants too were guessing about the pronunciation of this word, which can at least partly explain the difference in student and parent responses. Regarding aloof it is questionable whether all the instances of $/ \Lambda /$ can be taken as examples of the tendency toward unrounding of rounded vowels already referred to, since this word was not part of the active vocabulary of these 
group I informants. Twenty-nine out of 30 volunteered rooster for the 'adult male domestic fowl', and three suggested 'rooster fight' and 'fighting rooster', steering clear of $\operatorname{cock} .{ }^{9}$ Two group II informants had / $/$ in spook.

Allen found four instances of $/ 0 /$ among his Minnesota informants, and suggested that they were probably directly the speech of the Scandinavian parents of one of his informants, and of the German-born parents of the other three. The two group II informants both have Minnesota-born parents (from Austin, Albert Lea, McLeod), so that it seems that the $/ U /$ in spook can no longer, if ever, be ascribed to "foreign" influence. But one cannot rule out the possibility that these speakers may be influenced by grandparents and neighbours in the largely German McLeod area, and the largely Scandinavian Albert Lea area.

It was mentioned at the beginning of this paper that one object was to see if there is a laxing process at work. Ten of the 24 words, which are also dealt with in UM, will be looked at from this point of view. Four of them do not show any laxing; six of them do, more or less conclusively. The four words are spook, broom, room, hoop. Spook was pronounced /spuk/ by four (out of 65) Minnesota speakers in $U M$; and by two (out of 75) in my material. (See comments on spook in the preceding paragraph.) Broom was pronounced / brum/ by $10 \%$ of my informants. The percentage is somewhat higher in $U M$. However, the distribution $/ \mathrm{u} / \mathrm{J} / \mathrm{u}$ is less clear than appears from the percentages. The vowel of many of my informants was impressionistically midway between $/ 0 /$ and $/ \mathrm{u} /$, and the assignment of it to either $/ \mathrm{u} /$ or $/ \mathrm{u} /$ was therefore necessarily somewhat arbitrary. If broom (and room) had been pronounced in a context that provided different contrasts, or for a different interviewer, the percentage might have been different, but maybe not so much as to show a development toward laxing. (The $U M$ field workers also had the same problem.) Room: In my material there is $6 \% \mathrm{~J} /$; the frequency in $U M$ is somewhat higher. Hoop: Only $1 \%$ of my informants has $/ 0 \%$, compared with $48 \%$ of the Minnesota speakers in $U M$. Although $/ \mathrm{u} /$ "seems to find slightly greater favor among the better educated" (Allen, op.cit., Vol. 3, p. 251) where $/ 0 /$ and $/ u /$ compete, and nearly all my informants are in this category, there seems to be a clear case of / $\mathrm{u} /$ gaining ground in this word. In other words a case of tensing. A possible explanation for this development is analogy with other words that end in a bilabial stop: coop, droop, look, poop, scoop, stoop. 
(For the importance of phonetic environment see the last but one paragraph of this paper.)

The words that show laxing are butcher, Cooper, root, soot, hoof, roof. As one would expect the eastern folk variant $/ \mathrm{u} /$ in butcher, which was a declining pronunciation when the fieldwork for $U M$ was carried out 1947-53 (three type I informants), does not occur in my material. (See comments on unrounding above.) Cooper: Three of my informants have / / compared with only one Minnesota speaker in $U M$, and that one had an Alabama father. (/'kupər/ is a typically Southern and South Midland pronunciation.) Root: There is a noticeably lower frequency of $/ \mathrm{u} /$ among group I and II informants than among the parents: $16 \%$ and $37 \%$ respectively. The average occurrence of the short/lax vowel is $81 \%$, compared with $75 \%$ among the Minnesota speakers in $U M$. Hoof: The average occurrence of $/ 0 /$ in my material is $92.5 \%$, compared with ca. $80 \%$ in UM. Roof: As with hoof there is no significant difference between younger and older speakers in my material, but the present $82 \% / 0 /$ compared with ca. $65 \%$ in $U M$ indicates laxing over the last generation. Soot: $U M$ has $25 \% / \mathrm{u} /$ for the Minnesota informants, and the present investigation only $\mathrm{I} \%$; a clear case of laxing. To sum up: Of the ten words that were investigated for recent trends in Minnesota speech, six indicate that there is a laxing process still going on and four do not.

Nine of the informants in group I, all of whom had $/ U /$ in hoof, roof, thought that the pronunciation with / $\mathrm{u} /$ was "more correct", "more formal", "well educated". One mentioned having been taught /huf/ at school, as the "correct" form. Plural forms in /-vz/ were also felt to be more "correct". One informant would say /hufs/ to his friends, but / huvz/ to, e.g., his English teacher. This kind of attitude may explain the higher frequency of $/ \mathrm{u} /$ among group II informants, since it may have led them, in spite of the directions in the questionnaire, to put down $/ \mathrm{u} /$ rather than $/ \mathrm{N}$. Incidentally, this attitude may have influenced the responses of some of the parents, too. But it does not seem as if the efforts of teachers have stopped the pronunciations /huf/, /ruf/from gaining ground.

Although a number of group I informants think that it is more correct to say /huf/, /ruf/ than /huf/, /ruf/ it does not seem that education/social class affects the pronunciation of these words. There is no indication of this in the responses of the 19 parents. The four teachers, the attorney and the city manager among them all have /huf/, /ruf/.10 
All the informants were asked how they pronounced the plural forms of hoof, roof. The results appear in the table below.

Table 3. Pronunciation of the plural forms of $\mathrm{h}$ o of, $\mathrm{r}$ o of. (For informants, see Table 2.)

\begin{tabular}{|c|c|c|c|c|c|c|c|c|c|c|c|c|}
\hline & \multicolumn{3}{|c|}{ |-Ufs/ $(\%)$} & \multicolumn{3}{|c|}{$\left|-U_{v z}\right|(\%)$} & \multicolumn{3}{|c|}{$|-u f s|(\%)$} & \multicolumn{3}{|c|}{$/-u v z /(\%)$} \\
\hline & $\mathbf{I}$ & II & III & $\mathrm{I}$ & II & III & I & II & III & I & II & \\
\hline HOOF & 27 & 35.7 & 26.7 & 30 & 26.2 & 20 & 0 & 14.3 & 13.3 & 43 & 23.8 & \\
\hline $\mathrm{ROOF}^{\prime}$ & 53.3 & 59.5 & 53.3 & 13.3 & 4.8 & 6.7 & 10 & 14.3 & 20 & 23.4 & 21.4 & \\
\hline
\end{tabular}

Bergen and Cornelia Evans in their Dictionary of Contemporary American Usage maintain that the old plural hooves "is now used only in poetry" (p. 224). Kenyon \& Knott, op. cit., p. 207, has "rarely hooves". The first statement is not correct for any major U.S. speech area, and the second does not apply to Minnesota speech. Allen (op. cit., Vol. 2, p. 47) found that although hoofs was the dominant form in the $U M$ area, hooves was the customary pronunciation of $18 \%$ of the $U M$ informants. $(21 \%$ for Minnesota speakers.) As shown in Table 3 the situation is more complex than just the opposition between voiced and voiceless endings. One would expect long/tense / $\mathrm{u} /$ to occur with / $/ \mathrm{vz} /$, and short/ Iax $/ U /$ with $/$-fs $/$. Actually, all four combinations are found. There is quite a striking difference in the distribution of $/ \omega /$ and $/ \mathrm{u} /$ in the singular and the plural forms of hoof. (See Table 3.) The average of group I, II and III informants is: $92 \% / 0 /$ in the singular, $27.5 \% / 0 /$ in the plural. (Allen found that six informants who had the lax $/ 0 /$ in the singular had $/ u /$ in the plural.) The average figure for $/-\mathrm{fs} /$ is $39 \%$, and for $/-\mathrm{vz} / 61 \%$. This is a much higher figure than Allen's $21 \% \mathrm{l}-\mathrm{vz} /$, and indicates a change in the pronunciation of this form. Roof also has four plural forms, /rufs/ being the most common. In UM / - vz/ is less frequent among the least educated informants, but no social or regional contrast appears with any of these words in the present study.

The group I informants were asked to spell the plural forms of proof, spoof, hoof, roof, to see whether there was a one-to-one relationship between the spellings $-f s$, -ves and unvoiced - voiced endings respectively. They all suggested proofs, spoofs. (/pruvz/ was taken to be the 3rd person form of prove by all informants.) For hoof, roof the spelling -ves usually corresponds to $/-\mathrm{vz} /$, and $-f s$ goes 
with $/-\mathrm{fs} /$. But eight informants spelt the word with $-f s$ even if they pronounced it with a voiced ending, and six spelt -ves when the ending was unvoiced. Some of these students were uncertain about the pronunciation of these words.

The informants in group I were asked whether they had heard forms other than those that they themselves used for the words with variable pronunciation. Of the eight statements about the pronunciation of their parents that could be checked, three agreed and five disagreed (assuming that the parents' responses are fairly accurate). Judging from this, the other statements offered by these informants about somebody else's speech are probably not very reliable either, and have therefore not been referred to often.

The responses from the parents were compared with those of their children to see what kind of correspondence there was between them. The overall correspondence was $80 \%$. All the responses were similar for groom, hoop, soot, and varied for the remaining seven words, with woof not unexpectedly showing the biggest difference.

An equal number of males and females (38 and 37 respectively) was chosen in groups I and II to see if there might be any difference in their pronunciation of these words. Wolfram and Fasold have found that females tend to use stigmatised forms less frequently than males, and that they demonstrate a higher sensitivity to prestige norms. ${ }^{11}$ No statistically significant differences emerge from my data, which is interesting in view of what many informants said about the correctness of forms like /huf/, /ruf/ and the plural forms of these words. The responses do not show any sex differences, and the conclusion must be that in spite of some school effort at teaching the "correct" pronunciation the forms with $/ 0 /$ are not felt to be less prestigious by these informants.

In which phonetic environments does laxing most frequently occur? Judging from the words in Table II it appears that tense vowels most often become lax in front of an unvoiced consonant: $\mathrm{V}_{\text {tense }} \rightarrow \mathrm{V}_{\text {lax }} /-\mathrm{C}_{\text {unvoiced. }}$. No word in this list of the type $-\mathrm{C}_{\text {voiced }}$ is pronounced with $/ 0 /$ by as many as $10 \%$ of the informants. Of the words that are pronounced with $/ u /$ by only a very few speakers 16 are of the type $-\mathrm{C}_{\text {unvoiced }}$ and four $-\mathrm{C}_{\text {voiced }}$. Of the five words that all of the informants pronounce with $/ \mathrm{u} /$ four are of the type $-\mathrm{C}_{\text {voiced. }}$. However, a much larger corpus would be needed to determine whether this is a general tendency.

The scope of this paper is limited and it leaves many stones 
unturned. Laxing seems to be a fruitful area for further research. It would be necessary to work with a larger corpus than this one, and with, say, informants from all the major speech areas of the USA. The other pairs of tense - lax vowels should be investigated. A comparison of the development in American and British English might also yield interesting results.

\section{N O T E S}

1 This paper was written during a sabbatical spent at the University of Minnesota, Minneapolis. I am indebted to Professor J. L. Mitchell for suggesting this field, and for his generous advice. Professor Emeritus Harold B. Allen kindly read an earlier version of the paper and suggested numerous improvements.

2 The abbreviations Webster I, $\mathbf{1 1}$ and $\mathbf{1 1 1}$ do not ordinarily refer to these works.

3 The British English (BE) dictionaries have been included to show how laxing has influenced $\mathrm{BE}$ pronunciation. Apart from this comparison of dictionairies $\mathrm{BE}$ will not be dealt with in this paper.

$4 \mathrm{WI}$ has /hup/ (hoop) in the sense of 'lament, weep': /hUp/ is 'band of wood or metal', which is the meaning of it in all the ten entries. W 111 lists $/ \mathrm{u} /$, $\mid \mathrm{A} /$ in butcher and $/ \mathrm{A} /$ in roof as dialect.

5 There was no pagination in the edition available to me.

6 Webster went to England twice to do research for his dictionary work, so that he did have first-hand knowledge of London speech. But Walker had spent most of his life in that city and presumably had a more intimate knowledge of this English dialect.

7 The items in the parents' questionnaire were selected after the interviews, but before the responses from group II came in. In retrospect it appears that also spook, butcher and Cooper ought to have been included in the parents' questionnaire.

8 Iowa is the only Upper Midwest state in Grandgent's study.

9 H. L. Mencken has an amusing section on taboo words ("Forbidden words") in The American Language, of which oock is one.

10 This may perhaps seem a surprising conclusion, but it agrees with the findings of Raven I. McDavid, Jr.: "For many of the words derived from Middle English $/ 0: /-$ and some borrowings that have fallen into the pattern - both $/ \mathrm{u} /$ and $/ \mathrm{U} /$ occur, without social distinction, but with sharply differing regional patterns". (Language Learning, IV, p. 109).

11 The Study \& Social Dialects in American English, pp. 93-94.

\section{B I B L I O G R A P H Y}

1 Harold B. Allen. The Linguistic Atlas of the Upper Midwest. University of Minnesota Press, 1973-76.

2 Charles H. Grandgent. "More Notes on American Pronunciation", Modern Language Notes, Vol. vi, No. 8: 229-34.

3 Raven I. McDavid, Jr. "Some Social Differences in Pronunciation", Language Learning, IV : 102-16.

4 Walt Wolfram \& Ralph W. Fasold. The Study o Social Dialects in American English. New Jersey: Prentice-Hall, Inc., 1974. 